María del Pilar Lojendio-Quintero María del Pilar Mendoza-Ramos

\title{
Lucrecia: paradigma de castidad
}

Símbolo de ruptura entre dos momentos históricos de la antigua Roma, monarquía y república, Lucrecia se convierte en materia literaria de griegos, romanos, españoles, franceses, ingleses o alemanes en distintos tiempos: desde la Antigüedad grecorromana al Medievo, Renacimiento, Barroco o Romanticismo. ¿Cómo se forja la figura de Lucrecia desde la Antigüedad Clásica y el cristianismo hasta llegar a Christine de Pizan? Daremos respuesta a esta pregunta en el siguiente trabajo.

\section{Lucrecia en la antigüedad grecorromana}

Numerosas son las fuentes tanto en prosa como en verso que nos han transmitido con mayor o menor amplitud la historia de Lucrecia. No obstante, y atendiendo a la interpretación que se le da al episodio, proponemos dividir este amplio período en virtud de la ideología de los autores, esto es, escritores paganos y escritores cristianos, pues la protagonista de este suceso tendrá distinta consideración en unos u otros escritores.

\subsection{Escritores paganos}

Los autores que de forma más detallada nos han transmitido la historia de Lucrecia y han influido más en la literatura posterior son Tito Livio en prosa y el poeta Ovidio en verso. Sin embargo, con anterioridad Lucio Accio y Fabio Píctor, en verso y en prosa respectivamente, ya se habían ocupado de este personaje

Nota: Este trabajo se enmarca en el Proyecto de Investigación Modelos femeninos en los tratados didácticos medievales dirigidos a mujeres (Plan Propio del Vicerrectorado de Investigación de la ULL 2016) y en el Proyecto de Investigación FFI2016-76165-P de ayudas a Proyectos de I+D del Plan Estatal de Investigación Científica y Técnica y de Innovación 2013-2016.

María del Pilar Lojendio-Quintero - María del Pilar Mendoza-Ramos, Instituto de Estudios Medievales y Renacentistas (IEMYR), Universidad de La Laguna 
femenino; la obra de este último traducida del griego al latín en época de Cicerón, aunque hoy perdida, sirvió de fuente para Tito Livio y otros autores posteriores.

La estructura seguida por Tito Livio ( $A b$ urbe condita, I, 57-60) en su relato es la siguiente: ${ }^{1}$

(i) El episodio del muliebre certamen.

(ii) El acto de violencia cometido por Sexto Tarquinio.

(iii) Confesión y suicidio de Lucrecia.

El tono general del episodio narrado por Livio, como no podía ser de otra forma, es el propio de los relatos narrativos históricos, no ahonda en detalles personales, como sî lo hará Ovidio, aunque evidentemente no deja pasar aquellos que destacan en los protagonistas de la historia. Nuestra atención se centrará en las características del mundo femenino en general y de Lucrecia, como protagonista, en particular.

Muchas son las cualidades que se destacan en Lucrecia, pero, por encima de todas ellas, sobresale la castidad; no en vano es la peculiaridad que ha hecho inmortal a nuestra protagonista. En el texto de Tito Livio sólo encontramos dos veces la mención a la castidad de Lucrecia con el sustantivo castitas o el adjetivo en grado superlativo castissimus - a -um (... cum forma tum spectata castitas incitat, 57,11) у castissimum ... sanguinem ('Per hunc', inquit, 'castissimum ante regiam iniuriam sanguinem iuro ...' 59,1). En el primer ejemplo, la castidad de Lucrecia junto con su belleza inflama el deseo de Sexto Tarquinio, mientras que en el segundo, Bruto apela a la venganza contra la familia real tras sacar el cuchillo impregnado de la castísima sangre de Lucrecia.

En la primera parte del relato el autor utiliza, no obstante, otros mensajes que coadyuvan a destacar la castidad de Lucrecia. Así, en el campamento los hombres rivalizan en torno a la virtud de sus mujeres poniendo cada uno a la suya por las nubes (Suam quisque laudare miris modis, 57,6) hasta que Colatino, seguro de su esposa, manifiesta cuánto aventaja Lucrecia a las demás (... sciri quantum ceteris praestet Lucretia sua, 57,7). El resultado de la disputa pone en liza el contraste entre los personajes femeninos de la historia: unos, desdibujados y en un plano muy secundario, lo conforman las nueras del rey que disfrutan de un suntuoso banquete mientras sus maridos están en el campo de batalla (... regias nurus, quas in conuiuio luxuque cum aequalibus uiderant... 57,9), y otro lo protagoniza Lucrecia que, junto a sus esclavas, pasa la noche tejiendo en ausencia de su esposo, evocando abiertamente a Penélope (... sed nocte sera deditam lanae inter lucubrantes ancillas in medio aedium sedentem

1 S. Fontanarrosa, La fortuna di Lucrezia. Ricezione e attualizzazione di un modelo di virtù muliebre. 1. Tra Medioevo e Rinascimento, in “Aufidus”, 38, 1999, p. 115. 
inueniunt, 57,9). La primera parte del relato que, a modo de introducción, nos presenta a los personajes que intervienen en él, termina con la clara afirmación de la castidad de Lucrecia a la que acompaña la mención de su imagen física: la belleza. Esta combinación provocará el deseo en Sexto Tarquinio (Ibi Sex. Tarquinium mala libido Lucretiae per uim stuprandae capit; cum forma tum spectata castitas incitat, 57,10). Tal afirmación, que invita al lector a imaginar un ominoso desenlace, es el resultado de una sucesión de referencias que aluden al carácter de la protagonista y que el autor ha desgranado a lo largo de esta primera parte: Lucrecia aventaja a las demás esposas, porque, mientras las nueras del rey se divierten en banquetes, ella se dedica a tejer lana en su casa, además su belleza y castidad provocan el deseo lascivo en Sexto Tarquinio.

En la segunda parte (58), se produce la violación de Lucrecia por parte de Sexto Tarquinio. Aunque no aparece de forma expresa ningún término relacionado con la castidad, de nuevo Tito Livio hace uso de otros recursos lingüísticos. Así, ante las amenazas de muerte por parte de su violador, Lucrecia se mantiene firme incluso ante el peligro de una muerte segura (Vbi obstinatam uidebat et ne mortis quidem metu inclinari..., 58,4). Sin embargo, Sexto Tarquinio para vencer su 'virtud inquebrantable' (obstinatam pudicitiam, 58,5), la amenaza con la deshonra de un adulterio inexistente. ${ }^{2}$

En la tercera y última parte del relato, Lucrecia llama a su esposo y a su padre para referirles lo sucedido. Tito Livio nos presenta a una Lucrecia abatida (... Lucretia maesta tanto malo... 58,5 y Lucretiam sedentem maestam in cubiculo inueniunt, 58,6) que confiesa la pérdida del honor (... amissa pudicitia, 58,7). Sin embargo, a pesar del deseo firme de suicidarse, Lucrecia alega en su defensa que sólo su cuerpo ha sido violado, no su voluntad (... corpus est tantum uiolatum, animus insons..., 58,7), consciente, además, de que si no materializa su propia muerte, otras mujeres impúdicas podrían seguir su ejemplo (nec ulla deinde impudica Lucretiae exemplo uiuet, 58,10). A comienzos del capítulo 59, Bruto extrae el cuchillo empapado de la sangre castísima de Lucrecia.

El relato de Tito Livio presenta una estructura circular que comienza con una casta Lucrecia que tras la narración de la historia alcanzará esta cualidad en su grado sumo. ${ }^{3}$

Ovidio nos refiere la historia de Lucrecia con un lirismo del que está carente el texto de Tito Livio, como no podía ser de otra forma. La estructura de la historia

2 Sexto Tarquinio amenaza a Lucrecia con colocar junto a su cadáver el de un esclavo degollado y desnudo, para dar a entender que ha sido sorprendida en adulterio y, por eso, asesinada.

3 Los historiadores griegos que reproducen la historia de Lucrecia (Diodoro Sículo, Dionisio de Halicarnaso y Dión Casio), aunque presentan variantes con respecto al texto de Tito Livio, destacan, entre otros valores, la virtud y prudencia de Lucrecia. 
se desarrolla en Fastos II, vv. 721-852, y sigue la disposición que ya vimos en Livio:

(i) El episodio del muliebre certamen (vv. 721-766).

(ii) El acto de violencia cometido por Sexto Tarquinio (vv. 767-812).

(iii) Confesión y suicidio de Lucrecia (vv. 813-852).

El concepto de castidad se expresa principalmente por medio de los adjetivos pudicus $-a-u m$ (v. 757 y 794) у pudibundus $-a-u m$ (v. 819) en tres ejemplos distribuidos en cada una de las partes del relato: así el adjetivo sustantivado pudicam en la primera parte, nupta pudica en la segunda parte y pudibunda... ora en la última parte; los dos primeros casos cercanos al final, mientras que el tercer ejemplo hacia el principio, pues es el adjetivo castus (v. 841) el que cierra esta tercera parte de la narración. Estos términos inequívocos próximos al final cerrando cada una de las partes actúan como clímax, como culminación del carácter de Lucrecia que aparece esbozado en las líneas precedentes de forma menos explícita.

En el primer episodio de la historia (muliebre certamen), encontramos ya desde el comienzo alusiones que van dibujando la figura de Lucrecia. De la misma forma que en el relato de Livio, la rivalidad masculina se centra en la virtud femenina (quisque suam laudat, v. 731) y tan pronto como los hombres llegan al palacio, encuentran a las nueras del rey disfrutando de un banquete (Ecce nurum regis fusis per colla coronis / inueniunt posito peruigilare mero, vv. 739-740); mientras que Lucrecia junto a sus esclavas pasa la noche tejiendo (Inde cito passu petitur Lucretia, cuius / ante torum calathi lanaque mollis erat, vv. 741-742). De nuevo queda marcada la actitud opuesta de los personajes femeninos del relato, mientras Lucrecia espera la llegada del esposo hilando lana, imitadora de la fiel Penélope, las nueras reales se divierten disfrutando del vino y del banquete. Tras el lamento de la protagonista en un conmovedor estilo directo (vv. 745-754), Ovidio alude de forma expresa a la castidad de Lucrecia (lacrimae decuere pudicam, v. 757). El final de la primera parte se cierra con una descripción de la protagonista a los ojos de Sexto Tarquinio arrebatado de amor ciego por su belleza y carácter (niueusque color flauique capilli / quique aderat nulla factus ab arte decor / uerba placent et uox et quod corrumpere non est, vv. 763-765).

En la segunda parte, se materializa la violación de Lucrecia que, desconocedora de la intención de Sexto Tarquinio, recibe a su enemigo con la hospitalidad debida dado el vínculo de sangre que lo une a su esposo Colatino. La esposa pudorosa (nupta pudica, v. 794), a la que nunca antes habían tocado manos extrañas a las de su esposo (tum primum externa pectora tacta manu, v. 804), es sorprendida en plena noche por su violador armado con una espada. 
En la última parte, Ovidio refleja el abatimiento de la protagonista: sentada con el pelo alborotado (passis sedet illa capillis, v. 813), y, a los ojos de su padre y esposo, apenada y afligida como si preparase un funeral (utque uident habitum, quae luctus causa, requirunt, / cui paret exsequias, quoque sic icta malo, vv. 817818). La vergüenza por lo sucedido la lleva a ocultar su rostro pudoroso (pudibunda ... ora, vv. 819-820) y a narrar entre lágrimas lo que ella misma califica de deshonra (dedecus ... meum, v. 826). La Lucrecia deshonrada no puede sobrevivir a tal afrenta y, pese a que recibe de su padre y esposo el perdón por un hecho inevitable (dant ueniam facto genitor coniunxque coactae, v. 829), se da muerte con el puñal que había ocultado entre sus ropas. Incluso en ese instante, la casta protagonista se preocupa por no caer de forma deshonesta (tum quoque iam moriens ne non procumbat honeste / respicit, vv. 833-834). Finalmente, Bruto deseoso de vengar la muerte de la protagonista saca de sus entrañas el puñal empapado de su sangre pura (castum cruorem, v. 841).

\subsection{Escritores cristianos}

Los autores cristianos no desaprovechan la figura de Lucrecia y convierten su historia en exemplum paradigmático de castidad. Tertuliano, utilizando términos semejantes en los distintos pasajes en los que la menciona, ${ }^{4}$ no duda en alabar a la matrona romana, que ha preferido el suicidio a vivir con la mancha de la violación. En la misma línea se sitúa S. Jerónimo que considera a Lucrecia insigne por haber tomado la decisión de suicidarse para limpiar la mancha de la deshonra. ${ }^{5}$

No es, sin embargo, de la misma opinión S. Agustín (Ciu. 1,19) que utiliza el exemplum de Lucrecia de manera muy diferente. No muestra ninguna simpatía por ella y hace recaer sobre Lucrecia toda su misoginia y su oposición a los ideales de la cultura clásica. ${ }^{6}$ La crítica principal que el obispo de Hipona lanza contra Lucrecia se puede sintetizar en la siguiente pregunta: Si adulterata, cur laudata; si pudica, cur occisa? ('Si adúltera ¿por qué es loada? Y si es honesta ¿por

4 De feminis ad manum est Lucretia, quae vim stupri passa, cultrum sibi adegit in conspectu propinquorum, ut gloriam castitati suae pareret (Ad mart. 4, 1-4); Assidebit et illi matrona Romana, quae etsi per vim / nocturnam nihilo minus alium virum experta maculam carnis / suo sanguine abluit, ut monogamiam in semetipsam vindicaret (De mon. 17, 1-3); y uel Lucretia, quae etsi semel per vim et inuita alium virum passa est, sanguine suo maculatam carnem abluit, ne uiueret iam non sibi uniuira (De exh. cast. 13).

5 Ad Romanas feminas transeat et primam ponam Lucretiam, quae violatae pudicitiae nolens supervivere, maculam corporis cruore delevit (Adversus Iovinianum, I, 46) y ... et Lucretiam, quae amissa gloria castitatis, noluit pollutae conscientiae supervivere (Epistulae, CXXIII).

6 M. Otero Vidal, ¿Si adulterata, cur laudata ...?, in “Scriptura”, 12, 1996, pp. 33-50, p. 38. 
qué se mató? 19,7). A pesar de que S. Agustín era un defensor acérrimo de la castidad, el ataque a Lucrecia se basa en equiparar suicidio con homicidio. ${ }^{7}$ De esta manera y haciendo uso de su dominio de la retórica, el autor plantea que Lucrecia se suicidó no por exculpar su castidad mancillada, sino por deseo de gloria: ' $\mathrm{Y}$ siendo mujer romana, ávida de gloria en demasía ...' (et romana mulier, laudis auida nimium, 19,9). La intención del autor no es otra que enaltecer a aquellas mujeres cristianas que no tomaron la decisión de Lucrecia, esto es, el suicidio, sino que continuaron viviendo tras ser mancilladas ${ }^{8}$ ('No obraron así las mujeres cristianas, que habiendo padecido semejantes ultrajes, continúan viviendo sus días...'. Non hoc fecerunt feminae Christianae, quae pasase similia uiuunt... 19,10).

\section{Lucrecia en la literatura medieval francesa}

Al estudiar la presencia de Lucrecia en el marco medieval francés, ${ }^{9}$ se constata que su historia queda reducida generalmente a la función de ejemplo por lo que pierde gran parte del contexto que presenta en los autores clásicos. Se sigue, en general, el estilo de Tito Livio por lo que, como se ha señalado anteriormente, no se desarrollan los detalles personales más allá de las características básicas necesarias para definir al personaje.

En el caso de Roman de la Rose de Jean de Meun, la mención de Lucrecia, incluida en el discurso del Marido Celoso, está estrechamente relacionada con la de Penélope, de quien se dice escuetamente: "Penelope neïz prendroit/ Qui bien au prendre entenderoit;/ Si n'ot il meillor fame en Grèce” (vv. 8605-8607). ${ }^{10}$ Por su parte, ya sea porque se conoce menos o porque encaja más difícilmente en la argumentación a causa del suicidio, Jean de Meun presta más atención al caso de Lucrecia que se extiende por algo más de cuarenta versos, donde, además,

7 R. M. Marina Sáez, Personajes legendarios femeninos de la Roma Antigua en De civitate Dei de Agustín de Hipona: el ejemplo de Lucrecia, in Género y enseñanza de la Historia. Silencios y ausencias en la construcción del pasado, Madrid, Sílex, 2015, p. 301.

8 F. Fuentes Moreno, Lucrecia, in Mujeres reales y ficticias, Universidad de Granada, 2009, p. 107. 9 En su artículo titulado La historia de Lucrecia en prosa y en verso (in Dvlces Camenae. Poética y Poesía Latinas, J. Luque Moreno - Ma ${ }^{\mathrm{a}}$. D. Rincón González - I. Velázquez, Universidad de Granada, 2010, pp. 1359-1370), C. Martín Puente identifica todos los textos que contienen a este personaje. Son particularmente interesantes para este trabajo los de la Edad Media (p. 1362).

10 Guillaume de Lorris - Jean de Meun, Le Roman de la Rose, ed. de D. Poirion, Paris, GarnierFlammarion, 1974. Esta es la edición usada para todas las citas de este libro. 
menciona su fuente. ${ }^{11}$ Del personaje no se explicita ninguna virtud concreta, aunque se desprenden sus grandes cualidades ya que forma un binomio con Penélope, la mejor mujer de Grecia, por lo que se deduce que Lucrecia es la mejor mujer de Roma. Tras la afrenta a manos de Sexto Tarquinio, Lucrecia se presenta como un ejemplo para las mujeres y, en este sentido, en sus propias palabras, dice perdonarse el pecado, pero no la pena. Por ello, decide matarse, pero, antes del suicidio, alienta a sus familiares a vengar su muerte para que las mujeres tengan la seguridad de que, si son víctimas de una afrenta, se castigará al agresor.

Sin embargo, según la argumentación del Marido Celoso, estas grandes cualidades, trasladadas al presente del relato, no pueden más que declararse imperfectas y limitadas porque, aun a pesar de que el suicidio de Lucrecia sea una reivindicación de su virtud, no fueron sometidas a verdaderas pruebas para determinar su auténtico alcance: "Si n'est il mes nulle Lucrece,/ Ne Penelope nulle en Grece,/ Ne nulle prodefame en terre,/ S'il ert qui les seüst requerre” (vv. 8651-8654). Es decir, en último término, más que presentar la resistencia de la honestidad de Penélope o de Lucrecia como modelos, Jean de Meun da la vuelta al topos laudatio temporis acti y termina descalificándolos implícitamente al sostener que Penélope y Lucrecia pueden contarse como dos grandes dechados de honestidad porque en realidad no fueron objeto de un verdadero requerimiento como el que se lleva a cabo en su época.

Por su parte, en el tratado anónimo titulado Le Mesnagier de Paris, Lucrecia aparece como un claro ejemplo de castidad. En esta obra didáctica, concebida como manual de comportamiento por un esposo maduro para su joven esposa de quince años, se critican especialmente los vicios femeninos de la gula y la pereza y se ponen de relieve los atributos esenciales de la buena esposa: el cuidado en evitar la sospecha de mala conducta, la discreción y la castidad porque “... richesse, beaulté de corps et de viaire, lignaige et toutes les autres vertus sont peries et anichillees en femme qui a taiche ou souspeçon contre l'une d'icelles vertus". ${ }^{12}$ Precisamente, para ilustrar la castidad, el autor de este tratado escoge

11 En lo referente a las diferencias entre la Lucrecia de Tito Livio y la de Jean de Meun, E. Baumgartner señala que, antes del suicidio, en este último autor no se establece la separación entre el corazón y el cuerpo ni se menciona la pureza del alma. En este sentido, Jean de Meun presenta a Lucrecia sobrepasada por la mancha sufrida, lo que la conduce al suicidio “... non plus pour donner la mesure de sa vertu, mais parce qu'elle se sait, parce qu'elle se sent à tout jamais atteinte, marquée et corrompue par la violence qui lui a été faite” (De Lucrèce à Héloïse, remarques sur deux exemples au Roman de la Rose de Jean de Meun, in “Romania”, 95, 1974, p. 435). 12 G. E. Brerenton - J. M. Ferrier (ed.), Le Mesnagier de Paris, Paris, Le livre de Poche, Lettres Gothiques, 2010, p.150. Esta es la edición usada para todas las citas de este tratado. 
los actos, las costumbres y las buenas obras de varias mujeres como Sara, Rebeca, Lea, Raquel, Susana o la propia Lucrecia.

A pesar de que en sus fuentes, además de Tito Livio, se encuentran San Agustín (si bien de forma indirecta a través de Cessolis) y el Roman de la Rose, el autor del Mesnagier presenta a Lucrecia como un ejemplo de castidad en el matrimonio, como una mujer definida por su belleza y compostura, solo alterada por la alegría del regreso del esposo tras una larga ausencia. Todas estas cualidades la sitúan en el interior del hogar ("ou plus parfont de son hostel en une grant chambre loing de la rue”, p. 144) y, frente a las otras esposas que juegan o se entretienen conversando en la calle, la definen como una mujer doméstica y humilde. En este sentido, mientras el servicio de la casa hila la lana, Lucrecia, sentada, sola y aparte, se ocupa leyendo un libro de horas, lo que es una innovación de este autor que, frente a las representaciones clásicas del personaje hilando o cosiendo, busca incidir en su manual de comportamiento en los valores cristianos de la buena esposa. De esta forma, añade un rasgo nuevo, la devoción, al perfil clásico del personaje. Como complemento de estas características, Lucrecia se define también como una buena anfitriona y, así, ignorando las oscuras intenciones de su huésped, recibirá a Sexto de manera honorable.

Todos estos rasgos del carácter de Lucrecia se pondrán a prueba con la afrenta de la que será víctima y, por ello, pese a tener conciencia de su inocencia frente al deshonor ya que, según sus palabras, el corazón no participó en él, la profunda calidad de sus virtudes la conducirá a un juicio implacable: “Toutesfoiz, se mon corps es deshonnoré, ce n'est pas le cueur; et pour tant me absolz je du pechié, maiz non pas de la peine” (p. 146). Movida por esta determinación, Lucrecia, abatida ("car je ne suis jamaiz digne de vivre”, p. 148), presa del dolor, hará caso omiso de las palabras exculpatorias de su marido y, después de una última intervención, con la que incita a vengar su afrenta, se quitará la vida. Finalmente su suicidio, ${ }^{13}$ aún más que sus palabras,

13 Frente al puñal del que hablan Tito Livio o Jean de Meun, el autor del Mesnagier hará que Lucrecia se suicide con una espada, inspirándose probablemente en las miniaturas del Roman de la Rose. En este sentido, se debe señalar que algunos miniaturistas (como en el caso de los manuscritos Grenoble 608, fol. 75r; Douce 332, fol. 82v; et Morgan 948, fol. 77v et fol. 86r; o NKS 63, fol. 61r) van a reemplazar el puñal descrito en el texto por una espada, estableciendo así una relación con el suicidio de Dido. De esta forma, si bien las razones no son las mismas, sí lo son la frustración, la rabia y la determinación que conducen al suicidio en ambos casos (D. $\mathrm{M}^{\mathrm{a}}$. González Doreste - $\mathrm{M}^{\mathrm{a}}$. del P. Mendoza-Ramos, "Mort et mythe dans le Roman de la Rose de Jean de Meung: le texte et l'image, in La Mort dans la littérature du Moyen Âge, J. F. Kosta-Théfaine (dir.), Villers-Cotterêts, Ressouvenances, 2013, p. 457). 
se convertirá en un sacrificio que comprometerá a sus parientes a la venganza así como ocurre con la Lucrecia clásica. ${ }^{14}$

Finalmente, llegamos al Livre de la Cité des Dames de Christine de Pizan, obra que se presenta como la construcción metafórica de una ciudad inexpugnable llevada a cabo por la propia Christine y tres virtudes (Razón, Justicia y Derechura) para albergar en ella a las mujeres ilustres del pasado y, en menor medida, también del presente o futuro. En La Cité, Christine pretende demostrar la falsedad y el error de las acusaciones misóginas, especialmente las vertidas por Mateolo en su Liber Lamentationum Matheoluli, ${ }^{15}$ obra que esta autora presenta como la razón de la construcción de la ciudad. ${ }^{16}$

El Livre de la Cité des Dames sigue el modelo, frecuente a finales de la Edad Media, de catálogo exclusivamente dedicado a mujeres ${ }^{17}$ y se inspira especialmente en De claris mulieribus de Boccaccio, obra que, junto con el Decameron, tuvo una amplia difusión en Francia por medio de sus traducciones. En este catálogo, donde se presentan algo más de un centenar de mujeres ilustres, Lucrecia aparece como una esposa modélica, digna de ser recordada por su hermosura y, sobre todo, por su castidad, modestia y la honestidad de sus buenas costumbres. De esta forma, cuando recibe la visita de su marido junto con los demás hombres, la encontrarán hilando en compañía de la servidumbre y familia. Siguiendo el modelo latino, en su discurso antes del suicidio, el personaje de Boccaccio se absuelve de la culpa, pero no del castigo para evitar que en el futuro, tergiversando su historia, alguna mujer pueda encontrar excusa para sus malas acciones. ${ }^{18}$

14 M. Otero Vidal, “Si adulterata, cur laudata ... ?”, cit., p. 37.

15 Este compendio de tópicos misóginos de principios del siglo XIV, del que solo se conserva un ejemplar en la Biblioteca de la Universidad de Utrech, fue traducido al francés a finales de ese mismo siglo por Jean Le Fèvre (A.-G. Van Hamel, “Introduction”, in Les Lamentations de Matheolus et Le Livre de Leesce, de Jehan Le Fèvre, de Resson, París, Éditeur Émile Bouillon, 1892, tomo I, p. I). 16 En su batalla de desactivación de los prejuicios misóginos, Christine no olvida mencionar el Roman de la Rose, obra que, según sus palabras, goza de gran crédito a causa de la autoridad de Jean de Meun. Hay que recordar a este respecto que, en el siglo XIV, se multiplicarán las copias del Roman de la Rose de Jean de Meun, considerada por muchos como una enciclopedia. El Roman de la Rose está mencionado en la parte I, capítulo II (para criticar su diatriba contra el matrimonio), y, en la parte II, capítulo XXV (para oponerse a la idea de que las mujeres son incapaces de guardar un secreto) y capítulo LIV (donde se mencionan los escritos previos de Christine en contra de la obra de Jean de Meun: Épitre au Dieu d'amours y Épitres sur le Roman de la Rose, integrados en Querelle du Roman de la Rose).

$17 \mathrm{~J}$. Abed, Femmes illustres et illustres reines: la communication politique au tournant des XVe et XVIe siècles, in "Questes", 17, 2009, p. 52.

18 J. Boccaccio, De las mujeres illustres en romance, Zaragoza, Paulo Hurus, Alemán de Constancia, 1494, fo 52 v. y ss. 
Dentro de la concepción medieval de fondo común de la escritura donde no se citan explícitamente las fuentes, Christine de Pizan toma de Boccaccio aquellos ejemplos que le sirven para su objetivo y que, en su conjunto, representan casi tres cuartas partes de los modelos de mujer enumerados por el autor italiano. ${ }^{19} \mathrm{El}$ personaje de Lucrecia, que aparece en la segunda parte de $L a$ Cité,${ }^{20}$ constituye uno de estos préstamos. Gracias a él, Christine permitirá al lector de nuestros días conocer cómo interpretaban las mujeres de la época a este modelo femenino y, junto con otros ejemplos, servirá a esta autora para presentar el punto de vista de la mujer, de la víctima, sobre la violación. ${ }^{21}$

En esta obra, Lucrecia es descrita como una noble romana, la más casta de todas las mujeres de Roma (II, XLIV, p. 186), honesta, modesta y de maneras simples y distinguidas. Como esposa virtuosa, se encuentra en el interior del hogar vestida con un simple traje, entreteniéndose hilando la lana y conversando tranquilamente con las mujeres del servicio de la casa (II, LXIV, pp. 230-231). Después de la afrenta, como en las obras anteriormente mencionadas, en su justificación antes de hundirse el puñal en el pecho, y a pesar de ser capaz de probar su inocencia, Lucrecia sostiene que no quiere sustraerse a la vergüenza y al castigo para evitar que las "mujeres deshonradas y desvergonzadas" (p. 187) invoquen su caso como excusa. Además de la expulsión del rey y el fin de la monarquía en Roma, este suicidio tendrá como consecuencia, según Derechura, la promulgación de una ley que condenará a muerte al hombre que fuerza a una mujer, lo que, en palabras de esta Virtud, constituye "une peine légitime, morale et juste” (p. 186).

Por lo tanto, para Christine de Pizan, Lucrecia no es exactamente un referente de castidad. En realidad, para ilustrar esta virtud escogerá las historias de otras mujeres como Susana, Sara, Rebeca, Ruth o Penélope. Tampoco será un referente de belleza, rasgo que, en esta obra, aparece sobrepasado ampliamente por su virtud (p. 230). En realidad, Christine de Pizan reserva a Lucrecia una función más importante al presentarla como el ejemplo principal que ilustra la impostura del prejuicio misógino acerca de la violencia contra la mujer. ${ }^{22}$

19 A. Jeanroy, Boccace et Christine de Pisan: le De claris mulieribus, principale source du Livre de la Cité des Dames, in “Romania”, 189, 1922, p. 94.

20 Christine de Pizan, Le Livre de la Cité des Dames, E. Hicks - Th. Moreau (trad., intr.), Paris, Éditions Stock, 2000, p. 127. Esta es la edición usada para todas las citas de este libro.

21 M. Otero Vidal, “Si adulterata, cur laudata...”, cit., pp. 39-40.

22 Este es un claro ejemplo del método de trabajo de Christine de Pizan según el cual revisa la historia y solo utiliza de ella lo que necesita para la construcción de su ciudad ideal (Gl. M. Cropp, “Les personnages féminins tirés de l'histoire de la France dans le Livre de la Cité des Dames", in Une femme de lettres au Moyen âge. Études autour de Christine de Pizan, L. Dulac - B. Ribémont (eds.), Orleans, Paradigme, 1995, p. 205). 


\section{Conclusión}

En los relatos de Tito Livio y Ovidio, existe una serie de características sutiles que se insertan en la narración y refuerzan el modelo de castidad que representa Lucrecia. Así, la casta Lucrecia, en oposición a los personajes masculinos, se mueve en el ámbito doméstico: es en el hogar donde espera a su esposo y es en el hogar donde se produce la violación. Muy unido a la domesticidad está el carácter hospitalario de Lucrecia que la llevará a acoger al pariente de su marido, como marcan las normas de la sociedad de su tiempo. Frente a las otras mujeres que aparecen en la narración, Lucrecia espera a su esposo Colatino tejiendo la lana, correspondencia indudable con Penélope, no sólo la homérica, sino la que el mismo Ovidio retrató en Heroidas. Así, ámbito doméstico y trabajo de la lana se convierten en sinónimos referenciales de la mujer casta. El contrapunto lo establece S. Agustín que no consigue, sin embargo, arrebatarle a Lucrecia la consideración moral por la que ha transcendido hasta nuestros días.

Por su parte, los tres autores medievales franceses, siguiendo en mayor o menor medida el texto de Tito Livio, hacen un uso interesado de la historia de las mujeres mencionadas y, en nuestro caso, de la de Lucrecia: cada uno resalta aquella parte del ejemplo o aquel elemento que encaja mejor en su argumentación didáctica. Sin participar ninguno de ellos de la valoración desde la perspectiva cristiana de San Agustín, quien centra su atención en el suicidio y, como consecuencia, pone en duda la virtud del personaje, Jean de Meun se detiene en la posibilidad de la debilidad implícita de la honestidad y de la castidad de Lucrecia dentro de su discurso misógino; el autor del Mesnagier, en la fuerza de la honestidad y en la castidad del personaje como modelos de conducta cristiana; y finalmente, frente a estos dos autores que parten de un punto de vista masculino donde no se tiene en cuenta el sufrimiento y el perjuicio causado a la mujer, Christine de Pizan, yendo más allá de la simple exaltación de la castidad del personaje, incidirá en el punto de vista femenino sobre la cuestión de la violación mostrando el suicidio de Lucrecia como un acto de rebeldía, como la materialización de su rechazo de esta agresión contra la mujer. 